\title{
Cartografías literarias: anotaciones a propósito de la novela de migración mexicana
}

\author{
Literary Cartographies: \\ Annotations on the Mexican Migration Novel
}

\author{
Héctor A. Reyes ZaGa \\ Dickinson College \\ reyeszah@dickinson.edu
}

RESUMEN: Este artículo examina la representación de la experiencia migratoria de mexicanos en los Estados Unidos en la novela mexicana del siglo xx y xxı. Como primera parte se plantea una exploración crítica de los aspectos formales, estructurales y temáticos de la llamada literatura de migración, para después elaborar un mapa de la producción novelística mexicana de temática migratoria basado no sólo en la temporalidad literaria, sino en la interrelación que las obras guardan con los diversos momentos históricos de la migración mexicana.

\author{
PALABRAS CLAVE: \\ literatura de migración; \\ novela mexicana; \\ mapa literario.
}

KEYWORDS:

Migration literature;

Mexican novel;

Literary map.
ABSTRACT: This article examines the representation of the migration experience of Mexicans to the United States in the $20^{\text {th }}$ and $21^{\text {st }}$ century Mexican novel. The article first proposes a critical exploration of the formal, structural, and thematic aspects of the so-called migration literature, in order to later elaborate a map of Mexican novelistic production on migratory themes based not only on literary temporality, but also on the interrelation that the works maintain with the diverse historical moments of Mexican migration. 


\section{Entrada}

La migración ha sido constitutiva tanto de las culturas latinoamericanas como de los discursos que se han construido sobre ellas y que las construyeron. Desde los viajes coloniales hasta los desplazamientos actuales por razones políticas y económicas, la imagen del inmigrante ha ocupado en la narrativa latinoamericana un lugar paradójicamente central y marginal. Central porque ha servido de musa a escritores en la producción de sus obras, pero marginal, al mismo tiempo, debido a que la crítica literaria ha ignorado o devaluado su estudio. Dentro del corpus narrativo latinoamericano encaminado a representar las migraciones latinoamericanas, un caso que resalta entre la mayoría, es el de México, no sólo por su arraigada tradición de país expulsor de migrantes, sino por su rica y variada producción de obras literarias que se remonta al siglo xIx. Basta, como bien señala Javier Perucho, repasar las páginas de algunas de las crónicas de viajes de Ignacio Ramírez o Guillermo Prieto para descubrir en ellas la presencia del inmigrante mexicano y sus historias en territorio estadounidense (cfr. 2001: 19-20). Se puede decir, entonces, que la migración de mexicanos a los Estados Unidos ha sido recreada por autores mexicanos desde hace ya muchos años, siendo hasta ahora la segunda mitad del siglo xx el periodo de producción más rico para este tipo de escritura.

Pese a esta fertilidad literaria, resulta insólito la ausencia de reflexiones críticas articuladas a este tipo de narrativa. De hecho, según nuestra investigación, existen hasta ahora sólo unos cuantos estudios en México y los Estados Unidos destinados al análisis (a menudo parcial) de la representación del fenómeno migratorio mexicano en la literatura.

En México, por ejemplo, destaca principalmente la colección Tríptico del Éxodo, del escritor Javier Perucho, la cual rastrea, según el propio autor, la presencia de mojados, pachucos y chicanos en la narrativa mexicana del siglo xIx y xx (2001: 29). El estudio de Perucho es, sin duda, un esfuerzo significativo en la búsqueda histórica de creaciones literarias de temática migratoria; sin embargo, dentro de su colección se dejan fuera muchas obras importantes y se incluyen escritos en donde apenas se toca el tema de la migración. Asimismo, su investigación carece de un análisis detallado sobre la literatura de migración y sus características, dejando en 
consecuencia al lector con una imagen parcial de esta narrativa. También, es pertinente mencionar dentro de la crítica literaria mexicana a algunos otros manuscritos producidos por investigadores de la frontera norte que, si bien no examinan directamente la literatura de migración, arrojan información importante sobre obras producidas en el norte que tocan la temática migratoria. Entre ellos se encuentran, por ejemplo, Sociedad y desierto. Literatura de la frontera de Sergio Gómez Montero (1993); Texturas. Ensayos y artículos sobre la literatura de Baja California (2001) de Humberto F. Berumen y, finalmente, El norte: una experiencia contemporánea en la narrativa mexicana (2002) de Miguel Rodríguez Lozano. En el caso de los Estados Unidos, encontramos la investigación pionera de María Herrera-Sobek, The Bracero Experience: Elitelore versus folklore (1979) sobre la imagen del bracero en la literatura, la música y el testimonio oral; el artículo "Undocumented Crossings: Narratives of Mexican Immigration to the United States" (1998), de Alberto Ledesma, que aborda la representación del inmigrante mexicano desde la perspectiva chicana y mexicana, y finalmente el libro Hispanic Immigrant Literature: El Sueño del Retorno (2011) de Nicolás Kanellos que se enfoca en las características y el desarrollo de la literatura de migración producida por hispanos en los Estados Unidos. Todos los trabajos señalados anteriormente tocan de una u otra forma la literatura de migración mexicana, pero ninguno de ellos nos presenta una investigación sistemática sobre este tipo de escritura y su periodización histórico-literaria.

A lo que apunta este artículo es, entonces, a explorar la representación de la migración mexicana; es decir, lo que nos interesa es realizar un recorrido histórico sobre los textos ficcionales en español escritos por mexicanos durante los siglos Xx y xxI que han sido transitados de forma central por la temática del fenómeno migratorio mexicano. Para ello, planteamos en primer lugar una exploración crítica de los aspectos formales, estructurales y temáticos de la llamada literatura de migración, buscando en ésta aquellos elementos característicos presentes en la producción literaria mexicana. Una vez explorada, definida y caracterizada este tipo de literatura buscaremos elaborar un mapa de la producción mexicana de temática migratoria, en específico de la novela, basado no sólo en la temporalidad literaria, sino en la interrelación que las obras guardan con los diversos momen- 
tos históricos de la migración mexicana. ${ }^{1}$ La idea no es, por supuesto, convertir las periodizaciones en una estructura rígida, sino en una herramienta metodológica que nos permita una visión de lo que nos ofrece la literatura de migración a partir de los contextos históricos que se toman como referencia.

\section{La literatura de migración}

A pesar de que la literatura de migración es un género ${ }^{2}$ literario practicado ininterrumpidamente desde hace ya mucho tiempo, ${ }^{3}$ hasta ahora no existe unidad dentro de la crítica sobre su existencia, definición, temática o estructura narrativa. De hecho, las historias sobre migración han sido situadas en géneros tan disímiles como el epistolar, el pastoril, el autobiográfico, el de aprendizaje, el poscolonial y, por supuesto, el del viaje (White 1995; Pourjafari 2014). Histórica y sistemáticamente existe una cercanía de este género con muchos de esos tipos de literatura, especialmente, como señala Paul White, con la literatura de viaje, con quien comparte la voluntad de tematización del desplazamiento geográfico (5). Esas cercanías, sin embargo, no son, en nuestra opinión, suficientes para diluir, limitar o borrar un género literario. Debemos recordar, como apunta José F. Colmeiro, que los géneros literarios no son "categorías absolutas que se identifican con grupos cerrados, sino un conjunto de convenciones específicas compartidas" (39).

${ }^{1}$ Dada la amplia producción literaria basada en esta temática, este artículo incluirá sólo aquellas novelas en las que la migración (y sus protagonistas) hayan sido abordados de forma medular.

2 Hoy en día resulta complicado hablar de géneros literarios, principalmente en relación a la producción de obras después del Modernismo, debido a que no existen características formales para determinar qué obras pertenecen a determinado género. En general al hablar de un género nos referimos a una clasificación de las obras literarias que tienen una serie de aspectos comunes en su forma textual, que las diferencia de otras pertenecientes a géneros distintos. Sin entrar en un debate sobre si la literatura de migración es un género, un subgénero o simplemente un tema desarrollado por autores, consideramos, como veremos más adelante, que las diferencias existentes entre los textos narrativos de migración con respecto a los de cualquier otra categoría literaria, convierten a este tipo de literatura en una modalidad bien diferenciada; de ahí que al hablar de este tipo de escritura en este artículo utilizaremos intercambiablemente conceptos como género, literatura, categoría, etcétera.

${ }^{3}$ Algunos autores como Castaño Ruiz (2004) hablan, incluso, de relatos muy antiguos como los contenidos en la Biblia o textos pertenecientes a la antigüedad griega o latina como ejemplos de escritos que han transmitido movimientos de poblaciones. 
La literatura de migración, efectivamente, tiene en su origen y manifestación características compartidas con el conjunto de toda la literatura anterior a su existencia (como cualquier otra categoría literaria), pero son precisamente esas similitudes y desemejanzas que comparte con otros géneros, lo que nos permite hablar de la existencia de una literatura de migración. Normalmente cuando se caracteriza un género literario se atiende a cuestiones de índole temático-estructural. Se presta especial atención a su arquitectura narrativa, a las imposiciones temáticas, a la función de los personajes, etcétera. Por eso, por ejemplo, cuando la crítica literaria busca identificar un relato de viaje habla de la existencia de ciertos elementos característicos en la obra como pueden ser: la presencia de un viajero, el recorrido de un camino y la necesidad de un movimiento en el tiempo y el espacio (Frye: 31). Si uno hiciera el mismo ejercicio en una obra de temática migratoria también encontraría entre sus características dichos elementos, pero al mismo tiempo habría que mencionar muchas otras particularidades como, por ejemplo, la fusión morfosintáctica y semántica de dos o más idiomas presente, generalmente, en los relatos de migración y no así en los relatos de viaje. Entonces, pensamos que son el conjunto de las características intrínsecas del texto y su adscripción a un modelo codificador, es decir, a un "macrotexto", lo que nos permite hablar de literaturas particulares como la de migración.

Otra razón por la que se dificulta la unidad de criterios sobre la literatura de migración es la problemática de su propia definición. La correlación temática tan íntima con otros géneros literarios, así como la ambigüedad de su significado, han creado múltiples definiciones aparentemente irreconciliables. El problema principal radica en distinguir si la literatura de migración está constituida exclusivamente por escritos producidos por inmigrantes; por todas aquellas obras que incluyen inmigrantes en sus representaciones y construcciones; por los trabajos que tematizan de manera literaria el motivo de la migración o por la totalidad de la escritura que exhibe algún tipo de desplazamiento (ya sea real o simbólico). En este sentido, tenemos, dentro de la crítica literaria, a autores como Nicolás Kanellos que consideran como requisito indispensable de la literatura de migración el origen del escritor. Para Kanellos sólo tienen cabida dentro de este género aquellas obras escritas por inmigrantes: "Hispanic inmigrant literature is the literature created orally or in written form by immigrants from the Hispanic 
world who have come to the U.S. shores since nineteenth century" (2011: 7). ${ }^{4}$ La definición escrita, aquí citada por Kanellos, está obviamente orientada a la producción literaria hispana de los Estados Unidos, pero sobresale el hecho de la necesidad de que la obra tenga que ser escrita por un inmigrante para poder ser catalogada dentro de este género.

Al contrario de lo sugerido por Kanellos, autores como Leslie Adelson, Paul White y Saša Stanišić consideran intrascendente la condición jurídica del autor (inmigrante o nacional) al momento de definir la literatura de migración: "The literature of migration is not written by migrants alone [...]. Opposingly, a writer can be accounted for as a migrant artist in his own homeland" (Adelson: 23). ${ }^{5}$ Más bien, parecen inclinarse por la idea de establecer o fijar una serie de elementos estructurales y semánticos característicos de este tipo de literatura:

What distinguishes the migrant writers from the non-migrant is not the geographical borders and places, but the nature of their works. [Im]migrant literature can only be effectively discussed by subject matter, and in relation to the literary premises of genre, style, tradition, aesthetics and point of view (Stanišić: 1). ${ }^{6}$

La naturaleza de la obra y no la autoría de la misma, resulta, como se puede ver, el aspecto primordial en el momento de categorizar la literatura de migración. Finalmente, existen dentro de la crítica literaria escritores como Roy Sommer y Sten Moslund para quienes la literatura de migración poco tiene que ver con las historias reales de migrantes: "Migrant literature or transculture literature involves visions of the dissolution of fixed cultural identities and the assertion of cosmopolitan hybridization and ethnic fragmentation" (Moslund: 5). ${ }^{7}$ Para ellos lo primordial parece estar en el carác-

4 "La literatura de inmigración hispana es la literatura creada oralmente o por escrito por inmigrantes del mundo hispano que han Ilegado a las costas de los Estados Unidos desde el siglo XIX" (la traducción es mía).

5 "La literatura de migración no está escrita únicamente por migrantes [...]. Por el contrario, un escritor puede ser considerado como un artista migrante en su propia patria" (la traducción es mía).

6 "Lo que distingue a los escritores migrantes de los no migrantes no son las fronteras y lugares geográficos, sino la naturaleza de sus obras. La literatura de inmigración sólo puede ser discutida efectivamente con base en su temática y en relación con las premisas literarias de género, estilo, tradición, estética y punto de vista" (la traducción es mía).

7 "La literatura de migración o literatura transcultural implica visiones de la disolución de las identidades culturales fijas y la afirmación de la hibridación cosmopolita y la fragmentación étnica" (la traducción es mía). 
ter híbrido y poscolonial de los escritos ficcionales y en su capacidad de interrogar o reinterpretar lo canónico, lo cultural y las relaciones de poder.

Dada la amplia y confusa gama de opiniones críticas sobre este tipo de escritura, resulta preponderante rastrear todas aquellas características comunes presentes en este tipo de obras que nos permiten hablar de un género literario independiente. ¿A qué nos referimos entonces cuando hablamos de la literatura de migración? ¿Existe verdaderamente una literatura de migración? En nuestra opinión es válido hablar de una literatura de migración, es decir, de un género formado por un tipo particular de textos narrativos organizados en una trama argumental y ubicados en unas coordenadas espaciotemporales específicas, que giran alrededor de las migraciones y en los que se reflexiona de forma medular sobre las historias de vida de los inmigrantes.

Es este tipo de literatura una que reflexiona sobre el núcleo de las identidades nacionales y que narra las historias de vida de inmigrantes en relación con los acontecimientos del pasado reciente (Battistozzi: 445-452). Las obras, además, rescatan personajes y espacios marginales. Por eso se convierten en protagonistas el migrante-campesino, el migrante-ferrocarrilero, el migrante-indígena, el dirigente sindical, la mujer-migrante. Asimismo, la mirada se desplaza a los espacios fronterizos, a los barrios migrantes, a los mercados y las calles frecuentados, entre otros, por estos viajeros. Se trata, en muchos casos, de espacios públicos donde la historia personal se une con la historia nacional tanto del país de origen del migrante como del país al que inmigra.

La literatura de migración, además, no se preocupa solamente por mostrar la lucha individualista, sino que también busca presentar el esfuerzo de un grupo representativo, es decir, la conciencia grupal, y a veces la de una nación entera, por sobrevivir en esa nueva realidad desconocida que representa el país de destino (Ledesma: 108). Cualquiera que sea el número de los personajes que se abordan en este tipo de obras, su migración nace del deseo de escapar de una situación precaria hacia un nuevo mundo donde puedan alcanzar la libertad necesaria para una vida plena. Por eso, en primera instancia, los trabajos narrativos destacan la imagen idealizada de la nación receptora, imagen creada a partir de una información a veces incompleta, a veces tergiversada por otros inmigrantes. Sin embargo, conforme la trama avanza, y como consecuencia del trauma del desarraigo, el 
inmigrante comienza, también, a crear memorias e imágenes que evocan el pasado y agravan la nostalgia por su lugar de origen. De esta forma, podemos afirmar, siguiendo lo señalado por Kanellos, que la literatura de migración muestra una doble perspectiva: compara el pasado con el presente, la tierra natal con el país nuevo, su propia cultura con la del país recipiente, y equipara muchas veces la resolución de estos conflictos con el retorno a la patria del narrador, los personajes, el lector o la comunidad de inmigrantes (Kanellos 2011: 5).

La narrativa de migración trata entonces de preservar y fortalecer la cultura, la lengua y la lealtad hacia la tierra natal, mientras facilita el acomodamiento en el país receptor. De ahí que en este tipo de narrativa encontremos, en gran medida, la presencia de un nacionalismo apasionado, expresado frecuentemente a través del rechazo del inmigrante asimilado o del arrepentimiento de éste de haber dejado atrás su país de origen (56). Entre los temas predominantes resaltan: el viaje y cruce fronterizo; la descripción de las vejaciones y sufrimientos de los inmigrantes; la defensa de sus derechos humanos; la descripción de la ciudad; la diferenciación de clases sociales; el conflicto cultural; el intento por cuestionar la memoria, los conceptos de uno mismo y las ideas acerca de lo extraño; la asimilación o resistencia y la correspondiente promoción del nacionalismo; y finalmente la idea de hibridez identitaria o el "estar entre dos mundos".

Como se puede apreciar, todo lo planteado anteriormente nos permite darle un sentido de composición literaria a este tipo de narrativa, reforzando así nuestros planteamientos sobre la existencia de una literatura de migración capaz de ser aislada dentro la producción literaria. Una vez definida, explorada y caracterizada este tipo de literatura, elaboraremos un mapa histórico-literario de la producción novelística mexicana encuadrada dentro de la literatura de migración.

\section{Mapa histórico-literario de la novela de migración mexicana}

Por convivencia vecinal, experiencia migrante, exilio o simple interés, los escritores mexicanos han conocido la naturaleza de la vida allende el río Bravo, el desarraigo de los inmigrantes radicados en territorio estadouni- 
dense, $y$ han registrado en sus composiciones el trascurrir cotidiano de sus conciudadanos en los Estados Unidos. Aunque un número importante de escritores ha basado su narrativa en estas experiencias migratorias, resulta difícil constituirlos en generaciones específicas o grupos definidos por intereses comunes y propósitos estéticos. Difícil resulta también hablar de una fecha determinada en la que da inicio esta literatura en México, pues ya, como se mencionó, el siglo xix es testigo de la creación de algunas producciones literarias que tocan tangencialmente esta temática. Por eso nos parece que la forma más apropiada para explorar el corpus novelístico de la migración mexicana debe ser mediante la práctica de un ejercicio historiográfico vinculado a las diversas fases "reales" de la migración mexicana a los Estados Unidos. De esta forma, no sólo lograremos sistematizar la evolución histórica y cronológica de los escritos, sino además estaremos en posibilidad de mostrar los contextos históricos que toman como referencia las distintas obras creadas.

Para dicha tarea nos adscribiremos a las investigaciones realizadas por Jorge Durand $(2003 ; 2016)$ que señalan los principios del siglo xx como el punto inicial del éxodo mexicano a los Estados Unidos. De acuerdo a Durand la relación migratoria entre México y Estados Unidos puede ser analizada a la luz de seis grandes fases, a las que han correspondido diferentes políticas, modelos y patrones migratorios: la fase del enganche (1900-1920), la fase de deportaciones (1921-1941), el período bracero (1942-1964), la era de los indocumentados (1965-1985), la fase bipolar (1986-2007) y una última fase, iniciada en el 2008, que todavía está por definirse (Durand y Massey: 47-48). De las seis etapas, tres parecen agrupar a la totalidad de la producción novelística de migración escrita en México: la fase del enganche, el periodo bracero y la fase de los indocumentados.

En lo que sigue de nuestro artículo trataremos entonces de registrar las diversas creaciones novelísticas de migración mexicana producidas durante el siglo xx y xxI, vinculándolas temáticamente a las tres fases migratorias señaladas anteriormente. 


\section{La novela de migración en la fase del enganche (1926-1935)}

La fase del enganche arrancó a principios del siglo xx, durante el porfiriato, y se caracterizó por la combinación de tres factores que impulsaron el proceso de migración: el sistema de contratación de mano de obra privada y semi forzada, conocido como el enganche; la Revolución mexicana y el ingreso de Estados Unidos a la Primera Guerra Mundial que frenó la entrada de nuevos inmigrantes europeos y demandó mano de obra barata, joven y trabajadora proveniente de México (Duran y Massey: 47-48). La principal fuente de empleo para los inmigrantes mexicanos en aquel tiempo era la del traque o vía de tren. Los inmigrantes mexicanos eran contratados (legal o ilegalmente) en Estados Unidos para colocar rieles, construir terraplenes y dar mantenimiento a las líneas de ferrocarril (48). Aunque no hay consenso entre los investigadores sobre el número de inmigrantes mexicanos que trabajaron en esta industria, se estima que para 1909 representaban poco más del $17 \%$ de la fuerza laboral de mantenimiento de las líneas ferroviarias más importantes de los Estados Unidos (Palma Martínez: 237-238). Por supuesto, no sólo había inmigrantes mexicanos trabajando en este sector. De hecho, como apunta Sergio Martínez, además de los inmigrantes de clase rural que trabajaban en el traque o en la pisca de algodón, la Revolución mexicana produjo también conglomerados de exiliados "clasemedieros" o ricos que huyeron a los Estados Unidos para proteger sus bienes y a su familia de la inseguridad y violencia desatada en México en aquellos años (35).

Las primeras manifestaciones literarias mexicanas en materia de migración, producidas entre 1926 y 1935, están marcadas precisamente por este contexto social, de hecho, las historias no sólo nos presentan la experiencia de la migración como fenómeno demográfico, sino que además hay una exposición clara del entorno político, social y económico de México y los Estados Unidos. Un aspecto particular de este primer grupo de obras de migración es, además, el hecho de que cada uno de los autores llega en su momento a ser inmigrante o exiliado en la nación del norte. Esta particularidad intensifica la relación del autor con los personajes-migrantes y parece darle al lector una visión más real, más verosímil, del "mexicano de afuera". El uso del bilingüismo y los aspectos biculturales comienzan a ser utilizados también por los escritores como mecanismos narrativos para 
mostrar la problemática identitaria de los migrantes. Hay, además, en estas obras un claro intento por mostrar el maltrato que reciben los inmigrantes mediante la discriminación y el abuso laboral, pero también hay una crítica directa a aquellos inmigrantes que se dejan llevar por el sistema consumista estadounidense, y proyectan en sus novelas la idea de que el sueño americano difícilmente lo podrá alcanzar el inmigrante común. Finalmente, se puede decir que la característica principal de estas obras es su ideología de marcado conservadurismo. Los autores, a través de sus escritos, parecen buscar proteger al pueblo mexicano, al "México de afuera", de toda influencia perniciosa anglosajona. Les interesa la preservación de la religión católica y los valores tradicionales, el resguardo del mundo machista, la defensa de la integridad del idioma español y la exaltación del nacionalismo (Kanellos 2011: 3).

Tres son los trabajos novelísticos que de manera central representan la migración mexicana de principios del siglo xx: El sol de Texas (1926) de Conrado Espinoza; Las aventuras de don Chipote, o Cuando los pericos mamen (1928) de Daniel Venegas, y La patria perdida (1935) de Teodoro Torres.

La obra que inaugura la Ilamada literatura de migración en México es $E I$ sol de Texas (1926) de Conrado Espinoza, ya que es el primer trabajo que narra de manera central la vida de los inmigrantes mexicanos. La novela, compuesta de diecisiete capítulos, sigue la trayectoria de dos familias de inmigrantes, los García y los Quijano, que viajan a Estados Unidos durante la Revolución mexicana en busca de paz y bienestar económico, pero sólo encuentran discriminación, abuso y muerte. La obra de Conrado Espinoza nos presenta un reflejo histórico acerca de las vicisitudes del inmigrante mexicano en Estados Unidos durante la Revolución, pero se puede argumentar también que tiene otro aporte importante, que es mostrar la postura nacionalista existente en ese tiempo en la sociedad mexicana. Espinoza rechaza la actitud del inmigrante que va en búsqueda de riquezas y en su lugar pierde su identidad nacional y abandona su patria. Le resulta ilusoria la viabilidad de prosperidad en esos sujetos. Al contrario, ve en ellos una degeneración sociocultural al transformarse en una raza híbrida denigrante como la del "pocho" (Pluecker: VI-VII). ${ }^{8}$ De hecho, para

\footnotetext{
${ }^{8}$ La palabra se refiere a los inmigrantes mexicanos o sus hijos, que muestran evidencias de haberse aculturado a la sociedad estadounidense y que tienen dificultad para hablar el español.
} 
el autor, la posibilidad de crear y mantener un México fuera del espacio geográfico nacional resulta prácticamente imposible. Fuera de México, el mexicano pierde su dignidad, se corrompe y traiciona tanto a su patria como a sí mismo. El único camino digno para el inmigrante parece estar entonces en el retorno (Fernández: 610-611).

Dos años más tarde saldría a la luz en California, en el periódico El Heraldo de México de la ciudad de Los Ángeles, la novela hasta ahora más conocida de este periodo: Las aventuras de Don Chipote, o Cuando los pericos mamen (1928) de Daniel Venegas, quien logra, a través de la ironía, el estilo humorístico y un repositorio lexical extraordinario, representar las vicisitudes de los inmigrantes que abandonan a su familia para irse a trabajar al país vecino. Kanellos la interpreta como "un esfuerzo heroico por reivindicar al obrero mexicano inmigrado a los Estados Unidos y su cultura" (1999: 8). Y, efectivamente, la historia de don Chipote es una historia de vicisitudes y calamidades, como las que miles de mexicanos sufren en su intento de pasar a los Estados Unidos para, como señala el narrador, "barrer dinero con la escoba" (158). La novela narra las aventuras de don Chipote de Jesús María Domínguez, un campesino mexicano que emprende su camino a los Estados Unidos junto a su perro Sufrelambre, dejando a su esposa e hijos en su pueblo natal, para lograr riqueza, poder y éxitos rápidos en el paraíso norteamericano. Usando la estructura de la novela picaresca, Venegas expone a sus personajes ante distintos escenarios de los Estados Unidos de la década de los veinte (el cruce fronterizo, la modernidad de la ciudad, el "enganche" en las vías de tren, su transformación cultural, etc.) para ir mostrando las condiciones sociales en las que deben vivir aquellos que se atreven a dejar el lugar de origen, enfrentándose a la explotación y a condiciones humillantes de vida (Kanellos 1999: 8). El personaje recorre Texas, Nuevo México, Arizona y California para finalmente ser deportado por las autoridades migratorias y volver a México desesperanzado, sin dinero, fracasado y con un enorme sentimiento de culpa. El mensaje final de Venegas no podría ser más claro: el inmigrante logrará hacerse rico en los Estados Unidos "cuando los pericos mamen". Los aciertos literarios van más allá de la mera presentación de las historias de inmigrantes; de hecho, como bien lo apunta Perucho, la maestría de Venegas en el uso de giros idiomáticos, la novedosa inserción 
de anglicismos y sobre todo el uso del doble sentido mexicano, logran que la obra trascienda y sea capaz de ir más allá del público mexicano de Los Ángeles en 1928 (2000: 33).

Finalmente, la tercera novela, La patria perdida (1935) de Teodoro Torres, nos presenta una visión diferente a la de las anteriores. Ya no se trata de mostrar a los inmigrantes rurales y pobres que trabajaban en la construcción de vías de ferrocarril y en las plantaciones de algodón, sino a esos otros inmigrantes ricos y poderosos que se ven forzados a abandonar México por cuestiones políticas al irrumpir la Revolución mexicana. La historia gira alrededor de Luis Alfaro y su esposa, quienes, después de un ataque de los revolucionarios a su hacienda, deciden huir a los Estados Unidos en donde construyen su propio mundo "mexicano", su "México de afuera", en la Hacienda Bellavista, a las afueras de Kansas. Además de exponer esta otra experiencia migratoria, Torres demuestra a su vez en su novela la imposibilidad de recuperar la patria perdida, incluso para aquellos que tienen la oportunidad de regresar a México. Si en los trabajos de Venegas y Espinoza el regreso de los protagonistas a México parece ser el único camino digno para cerrar el ciclo migratorio, en La patria perdida, el regreso de Luis a México y su posterior retorno a los Estados Unidos —ante el desmoronamiento del México idealizado- parece indicarnos que para Torres "la patria se construye en el lugar presente" (González: 54).

\section{La novela de migración en el periodo bracero (1948-1956)}

La intervención de los Estados Unidos en la Segunda Guerra Mundial da inicio a la siguiente fase migratoria conocida como el periodo bracero. La repentina escasez de mano de obra estadounidense debido a la guerra y las altas demandas de su creciente industria propició que los gobiernos de México y los Estados Unidos instituyeran una especie de convenio colectivo de trabajo binacional. De acuerdo con las negociaciones, el gobierno de México se comprometía a organizar y canalizar el traslado masivo de inmigrantes a la frontera y los Estados Unidos debían ocuparse de garantizar sueldos, atender la salud y disponer de condiciones de trabajo dignas. Sin embargo, en la práctica dicho convenio no resultó lo que se espera- 
ba, ya que ni México tuvo la capacidad de organizar el traslado masivo de braceros, ni el gobierno estadounidense actuó frente a las continuas violaciones a los derechos de los trabajadores mexicanos. Según datos oficiales, entre 1942 y 1964 más de cinco millones de mexicanos trabajaron como braceros en los campos agrícolas estadounidenses, llegando a desplazarse en su punto culminante, más de 400,000 trabajadores anuales (Durand y Massey: 48).

Esta nueva etapa migratoria marca el surgimiento de un grupo de obras literarias producidas entre 1948 y 1956 que se concentran en el padecimiento de los braceros mexicanos. Se les conoce a menudo también como las "narrativas bracero", historias de mexicanos inmigrantes documentados e indocumentados que viajan a Estados Unidos, pero sólo por un tiempo, en busca de empleos que les permitan enriquecerse rápidamente (Ledesma: 107). Algunas veces las novelas de braceros buscan mostrar las vivencias del inmigrante durante su estancia temporal en los Estados Unidos; otras parecen enfocarse más en el choque cultural que viven estos peregrinos, pero en general, como bien lo apunta Herrera-Sobek, las historias suelen girar alrededor de los prejuicios, humillaciones y malos tratos que enfrentan los inmigrantes durante su paso por los Estados Unidos (36). Por eso, las novelas de esta fase tienden a presentar un tipo particular de inmigrante: masculino, joven, ignorante, temeroso, de origen rural y destinado a trabajar de manera temporal en el medio agrícola. El discurso está marcado también por los retratos negativos de los pochos. De ahí que al igual que en las novelas de la fase de enganche se presente un discurso narrativo nacionalista, que culpa a los estadounidenses de todos los infortunios de los migrantes. Además de esta tendencia nacionalista, la "narrativa bracero" está caracterizada también por hacer hincapié en la conciencia grupal de clase, y en las pruebas y tribulaciones de los mexicanos que luchan para sobrevivir en medio de la rapacidad capitalista (Ledesma: 108). Finalmente, sobresale en esta escritura la lección moral de que la promesa de fortuna de Estados Unidos es una promesa vacía. En la visión de estos autores, la posibilidad de prosperidad de los inmigrantes mexicanos resulta prácticamente imposible.

La novela que inaugura este segundo grupo de obras literarias de migración y, sin duda, la más emblemática de todas es Murieron a mitad del río 
(1948) de Luis Spota. En ella, el protagonista José Paván y sus compañeros nos llevan en una especie de road movie politizada por las diversas etapas de migración que viven los inmigrantes indocumentados en su deseo por llegar a los Estados Unidos: el viaje y la idealización de los Estados Unidos, la estancia en tierras estadounidenses y su confrontación con la realidad y, finalmente, el regreso a México y su desilusión total. La novela pretende ser una denuncia del trato de quienes, durante la vigencia del Programa Bracero, arriesgaron su vida para buscar mejores oportunidades en los Estados Unidos y encontraron ahí sólo discriminación, miseria, explotación y violación a sus derechos humanos. De algún modo lo que trasluce la narración de Spota es el rechazo a lo estadounidense, pero también hay una denuncia contra el proceder de los pochos, y de la propia policía mexicana que criminaliza al inmigrante y se aprovecha de su indefensión. A pesar de todo, como apunta Pardo Fernández, México se configura en la obra como el espacio idílico al cual volver (163).

Un año después sale a la luz la novela autobiográfica Aventuras de un bracero (1949) de Jesús Topete. El tono jocoso del autor difiere del estilo politizado de Spota, pero al igual que en Murieron a mitad del río, el texto nos presenta la experiencia de un bracero durante su estadía en los Estados Unidos. En este caso, el protagonista accede a este país de forma legal, a través del reclutamiento del gobierno mexicano, pero, según la información revelada al lector por el autor, la experiencia del protagonista resultará tan negativa como la de José Paván. Si para Spota la experiencia migratoria durante el periodo bracero semeja una forma de esclavitud, para Topete la vida del bracero se presenta como un contrato de servidumbre (Ledesma: 112).

En 1950 Héctor Raúl Almanza publica Huelga blanca, novela que, además de tocar el tema del "bracerismo mexicano", enfoca su atención en la lucha entre productores de algodón y acaparadores laguneros en Matamoros, Tamaulipas. Con una trama interpretada por dos campesinos mexicanos de nombre Felipe García y Martín Guerrero, Almanza dibuja paso a paso los pros y contras de aquellos campesinos que, empujados por el hambre, se ven en la necesidad de migrar al norte. El viaje de Felipe y Martín comienza en Parangaricutiro, Michoacán, y finaliza en el extremo sur de Texas en donde encontrarán trabajo cosechando papas en una 
granja estadounidense a cambio de veinticinco centavos diarios. Las experiencias de los protagonistas, al igual que en las dos novelas anteriores, presentan al lector varios eventos negativos: retención de salarios, hostigamiento, humillación, deportación, etc., pero es, sin duda, el encuentro que tienen los protagonistas con un residente mexicoamericano a principios de la novela, el evento más trascendente de la narrativa de Almanza, ya que nos revela la todavía dominante ideología nacionalista del México de los cincuenta.

Otra obra que aparece en la década de los cincuenta es El dólar viene del norte (1954), de José de Jesús Becerra González. La novela, a modo de una película holliwoodesca, nos cuenta la historia de Agustín Carranza, inmigrante campesino de una villa de Jalisco, que durante uno de sus múltiples intentos por cruzar la frontera sufre un golpe en la cabeza que le produce amnesia. La trama se centra en su intento por recordar lo sucedido meses atrás, después de ser llevado a su pueblo natal por un conocido que lo encuentra en la frontera. Conforme los recuerdos comienzan a surgir, el lector se va enterando de las desgracias que ha sufrido Carranza en sus cinco intentos por cruzar la frontera. Humillaciones, deportaciones, encarcelamiento, abusos y hasta una acusación por sospecha de ser un espía resumen los eventos de la vida del protagonista durante su estancia en los Estados Unidos. El final de la historia no podría ser más trágico. Una vez que Carranza recupera su memoria decide, de nueva cuenta, emigrar a los Estados Unidos para, finalmente, encontrar la muerte ahogado en el río Bravo. No hay, como señala Herrera-Sobeck, una sola nota positiva de la experiencia bracera en esta novela (4). El mensaje para el lector no podría ser más claro: evitar a toda costa emigrar a los Estados Unidos.

Finalmente, la última novela referente a esta fase migratoria es Tenemos sed (1956) de Magdalena Mondragón. La obra destaca no sólo por tratarse de la primera novela de migración escrita por una mujer, sino además porque la autora introduce de forma protagónica la migración de una familia nuclear. En efecto, en Tenemos sed somos testigos de la historia de Teófilo Aguirre y su familia durante su intento por llegar a los Estados Unidos en los años cincuenta. Impulsados por las falsas historias de riquezas obtenidas por inmigrantes durante el Programa Bracero, los integrantes de la familia intentan cruzar la frontera de forma clandestina; sin embargo, son 
capturados casi de forma inmediata al entrar a tierras estadounidenses. Una vez en los Estados Unidos la familia es encarcelada en un centro de detención, lugar en el que más tarde perderá la vida la menor de los integrantes. La muerte en la historia de Mondragón pasa a ser de esta manera protagónica, ya que como lectores somos confrontados no sólo con la historia trágica de Teófilo, sino, además, con todas esas historias de muerte y sufrimiento contadas a la familia por otros inmigrantes capturados antes que ellos.

\section{La novela de migración en la fase de los indocumentados}

Con el fin del Programa Bracero en 1964 da inicio un largo periodo en el que prevalecerá la inmigración indocumentada. Aunque técnicamente, como lo establece Jorge Durand (2016), existen dos fases diferenciadas después del fin del Programa Bracero: la fase de los indocumentados y la fase bipolar; pensamos que, dado el predominio en ambos periodos del fenómeno de la migración indocumentada, podemos hablar para efectos de este artículo de un solo período de migración. Esta fase migratoria que se extiende desde mediados de los años sesenta hasta el 2008 se caracteriza por la imposición unilateral —por parte de los Estados Unidosde cuatro medidas encaminadas a controlar el flujo migratorio mexicano: la legalización de un sector de la población trabajadora mediante la Ley de Reforma y Control de Inmigración de 1986 (IRCA); el reforzamiento de la frontera sur a través de las operaciones Bloqueo (1993) y Guardián (1994) y la aprobación la Ley Patriota en el 2001; la instauración de medidas restrictivas como consecuencia de la promulgación de leyes estatales (p. ej. Propuesta 187) y leyes federales como la Ley de Reforma de Inmigración Ilegal y Responsabilidad de Inmigración (IIRIRA) de 1996; y, finalmente, la deportación sistemática de los trabajadores inmigrantes indocumentados. Este período migratorio está caracterizado, además, por una diversificación en la población migrante. Ya no sólo vemos la migración rural masculina, como en los períodos anteriores, sino que ahora el inmigrante se diversifica en género, clase social y sector laboral. La migración deja de ser, además, completamente temporal, para adquirir carácter permanente, situación que da pie a un proceso de relativa integración a la sociedad de acogida. 
Otra característica de este período es el fortalecimiento de las mafias del narcotráfico y contrabando de personas. Esta situación ha incrementado el nivel de violencia contra los inmigrantes indocumentados, pues además de la ya conocida violencia institucional ejercida por autoridades de ambos países y de la intimidación ejercida constantemente por empleadores y grupos racistas estadounidenses, el inmigrante ahora tiene que enfrentarse a la brutal violencia practicada por las mafias de contrabandistas. Otro aspecto sobresaliente de este período es la aparición de una histeria antiinmigrante a nivel nacional, impulsada por la animosidad de muchos medios de comunicación. Finalmente, el factor quizás más importante en términos comparativos con otros períodos es el incremento exponencial de muertes de inmigrantes en su intento por llegar a los Estados Unidos.

Si bien las novelas de migración de esta última etapa comparten muchas de las características de las obras anteriores, es palpable también la presencia de elementos particulares que denotan una evolución en la visión del problema migratorio y en la propia forma de concebir la literatura. Una de estas transformaciones se da en el mensaje que el autor parece desplegar ante el lector. A diferencia de las novelas de migración de períodos anteriores, en donde los autores buscaban exaltar el nacionalismo mexicano, en estos trabajos ficcionales los escritores parecen ahora más preocupados por denunciar las desigualdades sociales y la reiterada violación de los derechos humanos de los inmigrantes, que en proteger la pureza de la identidad mexicana. De hecho, los autores de este período comienzan a enfocar su atención ya no sólo en lo sucedido en los Estados Unidos, sino en la problemática nacional que impulsa al inmigrante a dejar su país y en la violencia interna que afecta a los inmigrantes en su camino a los Estados Unidos. La diversidad de voces es otra sorpresa para los lectores de esta narrativa, ya que de obras producidas en el centro de México comienzan a surgir trabajos escritos desde otros estados; de hecho, se puede decir que la escritura producida en la frontera norte pasa a ser la protagonista de las novelas de migración indocumentada. Por eso, se puede apreciar en estas obras un esfuerzo por resaltar las características asociadas con la frontera. Se advierte también en este tipo de obras una experimentación narrativa, de ahí que encontremos en estas novelas particularidades como la multiplicidad de narradores, la presencia de nume- 
rosos desenlaces, la confluencia de distintos códigos culturales, etcétera. Lingüísticamente se puede apreciar en estos trabajos un constante juego del lenguaje, y la utilización de un vocabulario distintivo con vocablos como migra, ilegalidad, alien, cholo, narco, etc. El uso del inglés y/o el spanglish pasa a ser también una parte esencial de estas novelas. Históricamente este grupo de obras nos presentan en su trasfondo eventos como la promulgación de la Ley de Reforma y Control de Inmigración de 1986, la instauración de operaciones fronterizas, el inicio del Tratado de Libre Comercio (TLC), la guerra contra el narcotráfico o, incluso, los eventos terroristas del 11 de septiembre de 2001. Finalmente, en cuanto a la temática, además de la migración indocumentada, comienza a darse una exploración de la migración femenina e indígena, la presencia de inmigrantes en trabajos urbanos, el cruce fronterizo, el hibridismo cultural y la deshumanización del individuo.

La novela que abre esta nueva fase migratoria es Los fabricantes de braceros (1980) de Herminio Corral Barrera. En realidad, la obra funciona como una bisagra entre el período bracero y la fase de los indocumentados, ya que, a pesar de su título, más que hablar del movimiento masivo de inmigrantes de mediados del siglo xx, el autor hace uso del término bracero para referirse al inmigrante ilegal o indocumentado que comienza a desplazarse a los Estados Unidos a principios de los setenta. El argumento es fundamentalmente sencillo. Se trata de mostrar la vida de Juan Nepomuceno, un campesino pobre perteneciente al ejido El Coyote, ubicado en el estado de Chihuahua, que se ve en la necesidad de emigrar a los Estados Unidos de manera ilegal ante los abusos de los caciques de su localidad. A diferencia de las novelas anteriores, Los fabricantes de braceros pone especial énfasis en mostrar las condiciones de corrupción, abuso y pobreza existentes en el México de los setenta. De hecho, fuera del abuso laboral, la camaradería de los inmigrantes y el temor a la Patrulla Fronteriza, la obra muestra muy poco sobre la vida del inmigrante en tierras estadounidenses. Quizás la virtud que sobresale en la novela es el estudio y manejo del factor psicológico de los inmigrantes en su intento por llegar al otro lado. La obra posee, según Lupe Cárdenas, un "sentido inequívoco del profundo dolor, amor y sentimiento que se apoderan del ser en apariencia infrahumano [el inmigrante], a pesar de que este ser posee con 
frecuencia el más alto grado de dignidad y que encarna los verdaderos valores del honor y de la decencia sociales" (484-485).

De los ochenta hay un salto en el tiempo de más de una década para encontrar la siguiente novela que gira alrededor de la migración indocumentada; se trata de La luna siempre será un amor difícil (1994) de Luis Humberto Crosthwaite, la cual narra la historia de un conquistador español retirado de su oficio, Ilamado Balboa, y Xóchitl, una mujer azteca que quiere escapar del yugo familiar. Afectada por la mala economía, la pareja emprende un viaje migratorio en el tiempo, en autobús, desde la Tenochtitlán del siglo XVI hasta la Tijuana del siglo Xx, para ahí intentar reconquistar el norte del continente. La estancia de Balboa en tierras mexicanas fronterizas no durará mucho tiempo. Una vez que Xóchitl consigue trabajo en una maquiladora, Balboa cruza la frontera clandestinamente escondido en la cajuela de un coche, para emprender ahí su "cruzada militar". Sin embargo, la reconquista "al otro lado" nunca sucede y lo único que encuentra el conquistador es un trabajo como lavaplatos, el prejuicio de los habitantes de esas tierras y finalmente la deportación a manos de la PatruIla Fronteriza. La novela de Crosthwaite, como se puede ver, nos ofrece varios dispositivos para describir el complejo fenómeno de la inmigración indocumentada y sus reales consecuencias. Por un lado, tenemos la utilización de una figura histórica —el conquistador español—que, además de ironizar el tema de la migración, pretende concientizar al lector al mostrar que cualquier individuo, sin importar su estatus social, puede verse empujado en algún momento de su vida a migrar a otro país por cuestiones económicas. También tenemos la idea del sueño americano, imagen con la que juega el autor desde la ironía para revelar lo absurdo de su concepción. Finalmente, el autor muestra la frontera, una de sus mayores obsesiones escriturales, como una condición que los sujetos confieren a su particularidad histórica, geográfica y social.

En el mismo año se publica Callejón Sucre y otros relatos (1994), escrita por Rosario Sanmiguel, obra que nos presenta no sólo el tema de la inmigración indocumentada, sino que introduce de manera protagónica la migración femenina. Su libro - integrado por seis relatos y una novela corta- nos ofrece un abanico de sujetos femeninos migrantes que expande la perspectiva de la mujer como mera acompañante del varón. De 
hecho, Sanmiguel rearticula esta visión androcéntrica y nos presenta en su libro mujeres inmigrantes preocupadas más bien por la convivencia íntima consigo mismas y sus expectativas futuras de independencia. Su obra se caracteriza por una escritura "rupturista", producto de la utilización particular de variados recursos lingüísticos y narrativos. Esto se puede ver, por ejemplo, en su novela corta "El reflejo de la luna" cuya trama parece bastante sencilla: se trata de una abogada chicana casada con un empresario fronterizo, que prepara una demanda contra el hijo de un acaudalado estadounidense que intentó violar a una inmigrante mazahua. Sin embargo, si nos adentramos en la propia estructura de la obra, podemos apreciar su dimensión y complejidad. La novela consta de siete capítulos o secciones, cinco titulados en inglés y dos en español; situación que nos permite identificar el carácter polifónico del texto y la intertextualidad literaria y sociocultural que posee (Tabuenca Córdoba: 233). Asimismo, encontramos múltiples temporalidades que entrecruzan la historia de Sanmiguel. Mientras los capítulos nones representan los cuatro momentos del presente narrativo de la protagonista, los capítulos pares incorporan el cuerpo histórico de la novela al mostrar episodios del pasado de los distintos personajes. Finalmente, la propia estructura nos permite visualizar nítidamente la utilización de múltiples registros rítmicos, que van desde imágenes de tiempo detenido, es decir el silencio, hasta el movimiento incesante del cruce fronterizo (Barquet: 86-89). La novela de Sanmiguel, como se ve, no tiene nada que ver con el provincialismo escritural que ha venido caracterizando "supuestamente" a los narradores del norte de México. De hecho, a pesar de que su obra tiene como escenario la frontera México-Estados Unidos, en especial la de El Paso-Ciudad Juárez, se puede decir que las historias y los personajes creados por esta escritora chihuahuense rebasan las fronteras geográficas.

Un año después se publica La frontera de cristal (1995) de Carlos Fuentes, novela contada a través de nueve cuentos, donde se inspecciona profundamente la separación geográfica y espiritual que existe entre los Estados Unidos y México, y las consecuencias de la discriminación, el racismo, la violencia, y la fascinación mutua que existe entre ambas culturas. Fuentes ejemplifica en ella el drama de los indocumentados a través de varios de sus personajes: Lisandro Chávez, el limpiavidrios de Nueva 
York que se enamora de una estadounidense; Benito Ayala, el joven que al intentar cruzar la frontera ilegalmente se encuentra con un oficial chicano de la Patrulla Fronteriza; Gonzalo Romero, el coyote que muere a manos de un grupo racista estadounidense, entre otros. Pero es quizás Emilio Barroso quién encarna de manera más aguda la tragedia de la migración hacia Estados Unidos. Barroso, personaje de "La raya del olvido", es un anciano mudo e indocumentado que ha sido abandonado en una silla de ruedas en una raya imaginaria que marca la frontera física, sicológica y económica entre México y los Estados Unidos. Aquí aparece el Fuentes irónico, contrapesado con los agudos problemas de la inmigración durante los años del TLC, y los abusos que se cometen al otro lado del río grande, donde los mexicanos que lo cruzan creen hallar el paraíso que no alcanzan en su tierra.

A principios del siglo XXı aparecen dos trabajos que incorporan técnicas testimoniales, ficcionales y periodísticas para mostrar la vida de los inmigrantes indocumentados. Se trata de Diario de un mojado (2003) de Ramón "Tianguis" Pérez y Por amor al dólar (2006) de J. M. Servín. Basadas en las experiencias vividas por los propios autores durante su estancia en los Estados Unidos, ambas historias enfocan su atención en cuatro aspectos del fenómeno migratorio clandestino: la utopía prefigurada del espacio norteamericano, la marginalización y discriminación del inmigrante ilegal, el choque cultural del inmigrante tanto con los estadounidenses como con los hispanos residentes y el posterior retorno a México. Pese a sus claras diferencias (p. ej. migrante rural vs. migrante urbano), el narrador-migrante en ambas obras induce a su audiencia a que vea el mundo a través de sus ojos. De esa forma, logra un fuerte efecto de proximidad en la reconstrucción de las experiencias de la migración. Además, en cuanto a la construcción del discurso, es reveladora en ambos trabajos la presencia reiterada de un tipo de discurso que pondera las experiencias particulares como prueba de la condición casi heroica del personaje en que se desdobla el "yo" narrador al recrear su propia historia. Las dos obras nos presentan una nueva forma híbrida de aproximarse al fenómeno de la migración indocumentada, en la que, además de la ficción, vemos entrecruzadas otras formas de narración.

El caso de la novela Al otro lado, publicada en el 2008 por el escritor tijuanense Heriberto Yépez, es particular entre este grupo de obras, ya que 
vincula la temática migratoria con el narcotráfico y la adicción a las drogas. La historia se centra en la "Ciudad de Paso", espacio limítrofe donde radica el protagonista: Tiburón —adicto al phoco—, residente de una pensión habilitada por coyotes para hospedar a inmigrantes indocumentados. De ahí, el protagonista transporta al lector por un intenso viaje a las zonas marginales y más peligrosas de la ciudad con la intención de encontrar una forma de subsistir económicamente, antes de verse obligado a cruzar "al otro lado" como los inmigrantes ilegales con los que convive. Al otro lado no es, como se puede ver, una novela complaciente, va dirigida más bien a un público sensibilizado no sólo con el tema de la migración, sino con el conflicto del narcotráfico que en estos momentos atañe a todos los mexicanos. Su mérito está precisamente en presentar la cara de aquellos inmigrantes que sufren los efectos del negocio de las drogas.

En el 2009 se publica la novela Señales que precederán al fin del mundo (2009) de Yuri Herrera, hoy por hoy uno de los escritores jóvenes más reconocidos en México. La novela presenta la historia de Makina, una mujer de un pueblo en el sur de México, quien por petición de su madre se encamina en un viaje hacia los Estados Unidos para tratar de encontrar a su hermano que años antes había inmigrado al norte en búsqueda de mejores condiciones de vida. Al igual que en la novela de Yépez, en Señales que precederán al fin del mundo el tema del cruce fronterizo está acompañado de reflexiones sobre la violencia y el narcotráfico, pero el vínculo intertextual más poderoso lo encontramos en ese recorrido mítico realizado por los muertos para llegar a Mictlán en la cosmogonía Maya. De ahí que la historia presente al lector la posibilidad de una lectura desde diversos niveles. Tenemos por supuesto la del desplazamiento físico de un inmigrante, en este caso una mujer, que nos presenta el círculo migratorio tradicional. Está también presente el viaje de autodescubrimiento psicológico que le ocurre a la protagonista. Y finalmente se puede ver la dimensión mítica y religiosa que produce la muerte en un país como México. La novela se nos presenta, así, como un ejemplo de la forma en la que los jóvenes escritores se están aproximando a las problemáticas sociales que aquejan al país.

En el año 2010 aparece la novela Por cielo, mar y tierra de Ximena Sánchez Echenique, obra en la que se ligan tres historias de tres perso- 
najes distintos en tiempos y escenarios diferentes: Porfirio Díaz, Alfredo Palacios y Benigno Silva. Son tres protagonistas que enfrentan un destino en común: abandonar su lugar de origen. Porfirio Díaz, dictador de principios del siglo xx, que es obligado a abandonar su país por cuestiones políticas; Alfredo Palacios, estudiante universitario del México actual, que obtiene una beca de posgrado para estudiar en Europa; y Benigno Silva, un campesino zapoteca que decide cruzar ilegalmente la frontera para darle un mejor futuro a su pequeña hija Maite. La novela, construida sobre estas tres historias disímiles, hace uso de una segunda voz narrativa que lograr entrelazar la trama, de tal forma que los personajes terminan hablando con una misma voz: la voz del exiliado. Se trata, pues, de un texto que más que profundizar en el desplazamiento físico, ahonda en el perfil interior de los protagonistas, en especial en su lucha por controlar los sentimientos de nostalgia, desarraigo y pérdida de identidad que el viaje les produce. Los tres personajes buscan reconstituir un espacio tanto físico como simbólico que les resulte familiar y significativo lejos de la sociedad de origen. De esta manera, el discurso diaspórico que plantea Sánchez Echenique traslada la vivencia del desplazamiento y la recreación de un origen territorial y cultural lejos de la nación originaria. Pero no es, en nuestra opinión, ni el argumento, ni el mensaje lo que resalta en Por cielo, mar y tierra, sino el estilo narrativo de la escritora que, como bien lo apunta Carlos Olivares Baró, exhibe una mixtura de géneros (narrativa y poesía, principalmente) y logra una prosa en trote, rítmica, que rompe la supuesta ponderación entre significante y significado y edifica metonimias que huyen de las evidencias sociológicas (1).

Un año después, Iván Uriel Atanasio Medellín publica El Surco. Historias cortas para vidas largas (2011), novela de historias entrelazadas que presenta al lector las dos realidades de la migración que han afectado a México desde su formación como nación independiente: la migración al interior de México de campo a ciudad y la migración internacional hacia los Estados Unidos. Se trata, según el autor, de la primera entrega de una trilogía titulada "Apología del Encuentro", que aborda las relaciones humanas desde el ámbito de la migración. Bajo una estructura narrativa posmoderna que combina sociología, antropología e historia, los más de ochenta relatos contados por Medellín encuentran su vínculo en la histo- 
ria de José Guadalupe, un inmigrante mexicano poblano que, al igual que el propio autor, viaja a los Estados Unidos en busca del sueño americano. A lo largo de la novela aparecen personajes de 17 estados del país, con 25 narradores diferentes que incluso van cambiando el acento según la zona geográfica de la que provienen. La narración se realiza a través de la voz de una niña que conforme avanza la trama va madurando y consecuentemente se va apreciando una transformación en su discurso narrativo. Pese al extenso número de personajes que se presentan en la novela, lo que resalta de forma inmediata para el lector es la idea de un personaje colectivo: el migrante mexicano, que es exhibido como un sujeto explotado, golpeado, que vive en la incertidumbre constante, pero que posee una enorme fortaleza espiritual. En este sentido, la novela nos hace recordar la célebre obra chicana ...y no se lo tragó la tierra de Tomás Rivera, no sólo por la construcción de este personaje colectivo sino también por la experimentación narrativa utilizada por el autor. En El Surco. Historias cortas para vidas largas, la historia no es contada a través de capítulos, como tradicionalmente se hace, sino a través de las horas, del tiempo real de una jornada de trabajo. La primera crónica inicia a las 5:45 a. m., y bajo este horario se desarrollan sucesivamente las historias de vidas de todos los individuos y familias que aparecen en la novela. El libro, como se puede observar, aborda diversos temas escritos a través del dolor, el sacrificio y el esfuerzo de los migrantes. También tiene tintes de vacío en el amor, la ilusión y la esperanza, pero el mensaje final, como lo menciona el propio autor, es que al terminar la lectura el lector reflexione y tenga un alto nivel de introspección, un viaje a su interioridad y a la conciencia de lo importante que son los migrantes para México, para América Latina y para el mundo (1-2).

Finalmente, el último trabajo dentro de este mapa literario es la novela Campeón gabacho (2016) de Aura Xilonen. La obra, ganadora de la primera edición del Premio Mauricio Achar/Literatura Random House 2015, centra su narración en la vida de un adolescente migrante llamado Liborio, que vive en los en Estados Unidos en condiciones de pobreza y desposesión. Según la trama, Liborio se ve obligado a inmigrar ilegalmente a los Estados Unidos a los 17 años después de haber pasado en México una niñez en situación de calle y haber cometido un asesinato imprudencial. Una vez en los Estados Unidos el protagonista comienza a trabajar en una 
librería de segunda mano, propiedad de Chief, un personaje un tanto escandaloso pero bondadoso, que lo introduce al mundo literario. A partir de ahí, el eje de la novela se concentra en la relación de Liborio y Aireen, mujer de la que se enamorará profundamente, y en las peripecias que llevan al personaje principal a convertirse en un boxeador amateur. La novela, como se aprecia, carece de hondura respecto a la temática de la migración, de hecho, como lo apunta Nora de la Cruz, no hay "una observación profunda de la migración, la alienación o la violencia" (2); sin embargo, su obra presenta muchos otros atributos, como, por ejemplo, la construcción casi cinematográfica de las anécdotas, la presencia de un estilo rítmico melodioso en la escritura y sobre todo, la utilización de una lengua propia que en ocasiones parece emular los recursos del glíglico de Julio Cortázar. Xilonen se vale de la tradición oral mexicana y crea un vocabulario nuevo y una sintaxis distorsionada, que siempre es un reto para el lector. Su verbosidad pirotécnica incluye una amalgama de jergas y giros lingüísticos de varias regiones de México, así como combinaciones de pachuco, chicano spanglish, ingleñol, inglés, español arcaico, e incluso expresiones y palabras de algunos géneros populares de literatura del siglo XVI y XVII. EI lenguaje de Xilonen es, pues, el factor genuino que aporta realidad social a las historias de Liborio. La autora, de esta manera, consigue el propósito de convertir la tradición oral del inmigrante mexicano en imagen escrita, seduciendo al lector no sólo por lo que dice sino por cómo lo dice.

\section{Salida}

Quisiera concluir este artículo haciendo énfasis en la importancia de reconocer esta que Ilamamos literatura de la migración, no sólo por el hecho de que la misma exhibe las representaciones de los trayectos, derroteros o itinerarios de los actores sociales de la migración, la reconfiguración de identidades de estos sujetos, o da cuenta de nuevos elementos transculturales, sino porque de forma quizás más importante pensamos que en ella somos testigos de la noción de derechos que tienen los actores de la migración, de qué manera esta visión sobre los derechos se mantiene o modifica en el país receptor, y cómo trastocan éstos la experiencia migratoria en el lugar de origen. En el caso de la novela de migración 
mexicana es visible no sólo la vasta producción de obras orientadas a la temática migratoria, sino, sobre todo, obras que ostentan y denuncian un territorio espinoso dentro de las relaciones México-Estados Unidos marcadas por lo que Cacciari denomina la dialéctica de la política "hostis-hospes" (extranjero enemigo), y donde se cuestiona la validez de las políticas migratorias estadounidenses (1-2).

Nuestro trabajo también ha dejado claro el visible interés de los autores aquí referidos en reflejar los contextos históricos en los que se producen las historias narradas en sus novelas. En este sentido, el mapa literario historiográfico expuesto en este artículo evidencia la vinculación del corpus literario mexicano novelístico de migración con las diversas fases históricas del fenómeno migratorio mexicano. De esta manera, este artículo demuestra también cómo la literatura aporta a los investigadores de la temática migratoria nuevos elementos para la investigación por la forma en que los autores exponen y reflejan la realidad histórica de un momento determinado. En sentido general, ha intentado exponer que en todo proceso socio-histórico de una realidad determinada la literatura también contribuye a la investigación por constituir un reflejo del contexto que toma como referencia. La literatura, como lo formulan Cesarini y Federici (1988), ofrece, entonces, importantes soportes y modelos para comprender y representar la vida interior, la de los afectos, de las ideas, de los ideales, de las proyecciones fantásticas y, también, modelos para representar nuestro pasado, el de nuestra gente y el de los pueblos y la historia (28).

\section{Bibliografía}

Adelson, Leslie A. The Turkish Turn in Contemporary German Literature: Toward a New Critical Grammar of Migration. New York: Palgrave-Macmillan, 2005.

Almanza, Héctor. Huelga blanca. México: Academia Potosina de Artes y Ciencias, 1950.

Atanacio Medellín, Iván Uriel. El Surco. Historias cortas para vidas largas. México: Universidad Iberoamericana Puebla, 2011.

BATtISTOZZI, IsOlDA. "Novela argentina e inmigración: resignificación de la identidad inmigrante como respuesta a la experiencia represiva de los $70^{\prime \prime}$, en Romance Languages Annual. 10 (1998): 450-452.

Barquet, Jesús J. "La frontera en Callejón Sucre y otros relatos de Rosario Sanmiguel", en Revista de Literatura Mexicana Contemporánea. 2.5 (1997): 8593. 
Becerra González, José de Jesús. El dólar viene del norte. Guadalajara: Gráfica Editorial, 1954.

Berumen, Humberto Félix. Texturas: ensayos y artículos sobre la literatura de Baja California. México: Universidad Autónoma de Baja California / Plaza y Valdés, 2001.

CACCIARI, MASsimo. "La paradoja del extranjero", en Revista de Estudios Sociales. 8 (2001): 1-3.

CÁRDENAS, LuPE. "La deshumanización de los braceros en la novela Los fabricantes de Braceros", en Humanism and the Good Life: Proceedings of the Fifteenth Congress of the World Federation of Humanists. Arizona State University, 6-13 de marzo de 1994. Editado por Peter Horwath. New York: Peter Lang International Academic Publishers, 1998. 477-486.

Castaño Ruiz, Juana. "Discurso literario e inmigración: escritores y tipología de textos", en Tonos digital: Revista Electrónica de Estudios Filológicos. 7 (2004): $1-2$.

CesarinI, R. y L. De Federici. I/ materiale e l'immaginario. Laboratorio di analisi dei testi e di lavoro critico. Torino: Loescher, 1988.

Colmeiro, José F. La novela policíaca española: teoría e historia crítica. Anthropos, 1994.

Corral Barrera, Herminio. Los fabricantes de braceros. México: Editores Asociados Mexicanos, 1980.

Crosthwaite, luis Humberto. La luna siempre será un amor difícil. México: Eco, 1994.

De la Cruz, Nora. "Campeón gabacho, de Aura Xilonen: ruptura y convención", en Casa del Tiempo. 33 (2016): 67-69.

Durand, Jorge y Douglas S. Massey. Clandestinos. Migración México-Estados Unidos en los albores del siglo XXı. México: Miguel Ángel Porrúa, 2003.

Durand, Jorge. Historia mínima de la migración México-Estados Unidos. México: El Colegio de México, 2016.

Espinoza, Conrado. Under the Texas Sun / El sol de Texas. Houston: Arte Público Press, 2007.

FERNÁNDEZ R. DANIEL. "Narrativa mexicana y centroamericana en los Estados Unidos", en Enciclopedia del español en los Estados Unidos. Madrid: Instituto Cervantes, 2009.

Frye, NorThrop. Anatomy of Criticism. Princeton: Princeton University Press, 1957. Fuentes, Carlos. La frontera de cristal. México: Punto de Lectura, 2005.

GonzÁlez E., Karla. "Perspectivas de la Revolución mexicana en el exilio: el desencanto de los intelectuales en la narrativa mexicoamericana". Diss., The University of Texas, 2013.

Gutjah, ORTUD. "Literatura de la migración turco-alemana: un bosquejo", en Verbum et Lingua. 2 (2013): 48-65.

Herrera-Sober, María. The Bracero Experience: Elitelore versus Folklore. Los Ángeles: Universidad de California en Los Ángeles, 1979.

Herrera, Yuri. Señales que precederán al fin del mundo. México: Periférica. 2009. Kanellos, Nicolás. "Introducción", en Daniel Venegas. Las aventuras de don Chipote, o, Cuando los pericos mamen. Houston: Arte Público Press, 1999. 7-26. 
Kanellos, Nicolás. Hispanic Immigrant Literature: el Sueño del Retorno. Austin: University of Texas Press, 2011.

Ledesma, Alberto. "Undocumented Crossings. Narratives of Mexican Immigration to the United States", en David Maciel. Culture Across Borders: Mexican Immigration \& Popular Culture. Arizona: The University of Arizona Press, 1998. 91-134.

Martínez, Sergio M. "Movimientos migratorios masivos de México a Estados Unidos en tres novelas chicanas escritas en español", en Confluencia. 26.1 (2010): 34-46.

Mondragón, Magdalena. Tenemos sed. México: Revista Mexicana de Cultura, 1956.

Mostund, S. P. Migration Literature and Hybridity. London: Palgrave Macmillan, 2010.

Olivares Baró, Carlos. "Tres voluntades míticas del abandono", en La Razón. México, 3 de julio de 2010.

Palma Martínez, Enrique y Laura Mota Díaz. "Evolución de la respuesta institucional ante el fenómeno migratorio en México", en Ra Ximhai. 9.3 (2013): 235-259.

PARDO FERNÁNDEZ, RodRIGO. "La ficción narrativa de la frontera: el río Bravo en tres novelas", en Frontera Norte. 25.49 (2013): 157-178.

Pérez, Ramón. Diario de un mojado. Houston: Arte Público Press, 2013.

Perucho, Javier. Hijos del desastre. Migrantes, pachucos y chicanos en la literatura mexicana. México: Verdehalago, 2000.

Perucho, Javier. Hijos de la patria perdida. Pachucos, chicanos e inmigrantes en la narrativa mexicana del siglo Xx. México: Verdehalago, 2001.

PlueCKer, John. "Introducción", en Conrado Espinoza. Under the Texas Sun / El sol de Texas. Traducido por Ethriam Cash. Houston: Arte Público Press, 2007. $\mathrm{V}$-XXIX.

Pourjafarl, Fatemeh. "Migration Literature: A Theoretical Perspective", en The Dawn Journal. 3.1 (2014): 676-692.

Sánchez Echenique, Ximena. Por cielo, mar y tierra. México: Tusquets Editores, 2010.

Sanmiguel, Rosario. Callejón Sucre y otros relatos. Chihuahua: Ediciones del Azar, 1994.

Servín, J.M. Por amor al dólar. México: Joaquín Mortiz, 2006.

SOMMER, Roy. Fictions of Migration. Trier: Wissenschaftlicher Verlag Trier, 2001.

SPOTA, LuIS. Murieron a mitad del río. México: Grijalbo, 1987.

STANIŠIĆ, SAŠA. "Three Myths of Immigrant Writing: A View from Germany" (2008), en Words without Borders. Artículo en línea disponible en <http://wordswithoutborders.org> [consultado el 6 de marzo de 2015].

Tabuenca Córdoba, María Socorro. "'Callejón Sucre' y otros relatos de Rosario Sanmiguel", en Revista de Literatura Mexicana Contemporánea. 1.1 (1995): 110-115.

TOPETE, Jesús. Aventuras de un bracero. México: Secretaría de Educación Pública / Conasupo, 1949.

TORRes, TeOdOro. La patria perdida. México: Ediciones Botas, 1935. 
Venegas, Daniel. Las aventuras de don Chipote, o, Cuando los pericos mamen. Houston: Arte Público Press, 1999.

Walkowitz, ReBECCA. "The Location of Literature: The Transnational Book and The Migrant Writer", en Contemporary Literature. 47.4 (2006): 527-545.

White, PAul et al. Writing Across Worlds: Literature and Migration. London: Routledge, 1995.

Xilonen Arroyo, Aura. Campeón gabacho. México: Literatura Random House, 2016.

Yépez, Heriberto. Al otro lado. México: Editorial Planeta, 2008.

Héctor A. Reyes ZaGA

Es profesor investigador de los Departamentos de Español y Estudios Latinoamericanos de Dickinson College en Pennsylvania, Estados Unidos. Obtuvo su doctorado en Literatura Latinoamericana en la Universidad de Minnesota y cuenta además con una licenciatura en Derecho por la Universidad Iberoamericana en México. Se especializa en la literatura mexicana contemporánea y en los estudios fronterizos. Ha publicado diversos artículos en Estados Unidos y España. Su más reciente investigación "Teatro y derechos humanos: Representaciones de la experiencia migratoria mexicana en Los ilegales y El viaje de los cantores" fue publicada por la revista $A$ Contracorriente $A$ Journal on Social History and Literature in Latin America. 